\title{
Free convection flow and mass transfer over a vertical plate with radiation and uniform transpiration effects
}

\author{
Fardin Rouzbahani ${ }^{1}$ and Ali Asghar Khoramshahi ${ }^{2}$ \\ ${ }^{1}$ Department of Mechanical Engineering, Hamedan Branch, Islamic Azad University, Hamedan, Iran \\ ${ }^{2}$ Department of Mechanical Engineering, Brojerd Branch, Islamic Azad University, Brojerd, Iran
}

\section{Article history:}

Received date: 19 May 2020

Review date: 20 July 2020

Accepted date:25 July 2020

\section{Keywords:}

mass transfer, free convection, vertical plate, radiation, uniform transpiration

\begin{abstract}
In this present work the free convection flow and mass transfer over a vertical plate in with radiation and uniform transpiration, the surface of which is exposed to a constant wall temperature. The semi-similar solution of the Navier-Stokes equations, energy and concentration equations has been obtained numerically using by the implicit finite difference scheme of Crank-Nicolson's type. Numerical results are presented by velocity, temperature and concentration distributions of the fluid for a wide range of radiation parameter, thermal Grashof number, mass Grashof number, Prandtl number and Schmidt number. The local skin friction, Nusselt number and Sherwood number are also presented graphically. It is observed that, when Prandtl number increases the velocity and temperature decrease in the boundary layer. Also, it is found that as increase in the radiation parameter leads to increase in the velocity field and rise in the thermal boundary thickness.
\end{abstract}

Please cite this article as: Rouzbahani F., Khoramshahi AA. 2020. Free convection flow and mass transfer over a vertical plate with radiation and uniform transpiration effects. SRPH Journal of Fundamental Sciences and Technology, 2(3), 11-24

\section{Introduction:}

The process of free convection flow and mass transfer over a vertical plate with radiation and uniform transpiration effects an important role in the design of chemical processing equipment, nuclear reactors, and formation and dispersion of fog. A detailed discussion on this topic can be found in Soundalgekar VM and Wavre PD [1], Raptis [2], Gokhale [3], Takhar et al. [4], Gebhart. [5], Callahan and Marner [6], Soundalgekar and Ganesan. [7], Ekambavannan [8], Birajdar et al. [9], and Sacheti et al.[10] considered the mass transfer effects on flow past an impulsively started infinite isothermal vertical plate with constant mass flux. Sattar et al. [11] presented a numerical solution to the problem of free convection flow past an impulsively vertical plate in porous media and in the presence of variable suction. Emad et al. [12] investigated the MHD free-convection flow of a non-Newtonian power-law fluid at a stretching surface with a uniform free-stream. Abd et al. [13] obtained the numerical solutions for the radiation effects on MHD unsteady free-convection flow over vertical porous plate. Kim [14] developed the numerical solutions for Unsteady MHD convection flow of polar fluids past a vertical moving porous plate in a porous medium. Sharma and Singh [15] investigated the Unsteady MHD free convection and heat transfer along a vertical porous plate with variable suction and internal heat generation. In this continuation, Numerical solution of unsteady MHD flow past a semi-infinite isothermal vertical plate was investigated by Ganesan and Palani [16-17]. Numerical solution of the effects of mass transfer on the MHD flow past an impulsively started infinite vertical plate with variable temperature or constant heat flux was investigated by Shanker and Kishan [18]. Takhar et al. [19] analyzed the Unsteady mixed convection flow from a rotating vertical cone with a magnetic field are obtained. Elbashbeshy [20] analyzed the Heat and Mass transfer along a vertical plate with variable surface tension and concentration in the presence of the magnetic field. Motivated by the above investigations the present paper aims to study the combined free convection flow and mass transfer over a vertical plate with radiation and uniform transpiration effects. The flow in the fluid is caused due to the uniform motion of the plate. Numerical solutions are derived for the velocity distributions, temperature, and concentration fields by using the implicit finite difference scheme of Crank-Nicolson's type. The present study is of course of great practical and technological importance, for example, in astrophysical regimes, the presence of planetary debris, cosmic dust, and so forth and creates a suspended porous medium saturated with plasma fluids. Combined radiation and heat and mass transfer, due to temperature and concentration 
variations with free convection flow in fluid-saturated porous plate, has several important applications in a variety of engineering processes including heat exchanger devices, petroleum reservoirs, chemical catalytic reactors, solar energy porous water collector systems, and ceramic materials.

\section{MATHEMATICAL ANALYSIS}

Consider the free convection flow and mass transfer on a vertical plate with radiation and uniform transpiration effects and constant wall temperatures (Fig. 1). Under these assumptions and Boussinesq's approximation, the flow is governed by the following system of equations:

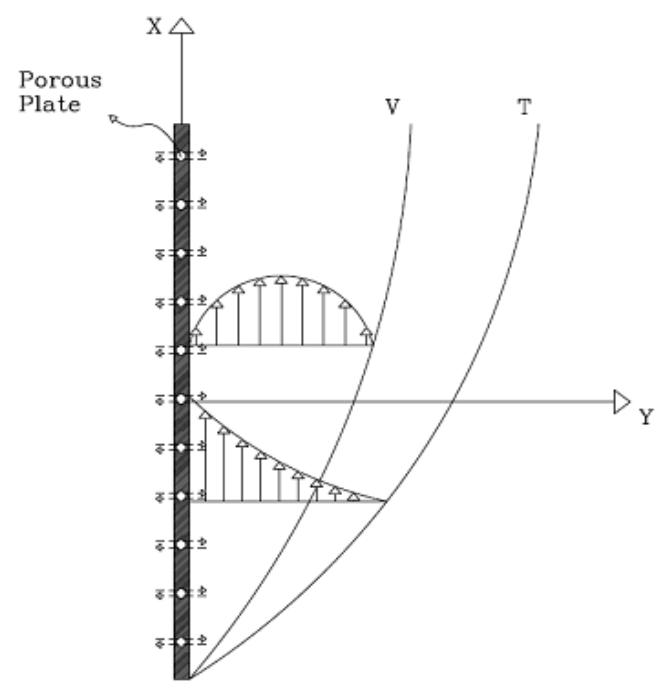

Fig (1) Sketch of the physical model

Continuity equation:

$$
\frac{\partial u}{\partial x}+\frac{\partial v}{\partial y}=0(1)
$$

Momentum equation:

$$
\text { (2) } \frac{\partial u}{\partial t}+u \frac{\partial u}{\partial x}+v \frac{\partial u}{\partial y}=v\left(\frac{\partial^{2} u}{\partial x^{2}}+\frac{\partial^{2} u}{\partial y^{2}}\right)+g \beta_{T}\left(T-T_{\infty}\right)+\beta_{C}\left(c-c_{\infty}\right)
$$

Energy equation:

$$
\frac{\partial T}{\partial t}+u \frac{\partial T}{\partial x}+v \frac{\partial T}{\partial y}=\bar{\alpha} \frac{\partial^{2} T}{\partial y^{2}}-\frac{1}{\rho C_{p}} \frac{\partial q_{r}}{\partial y}
$$

Concentration equation:

$$
\frac{\partial c}{\partial t}+u \frac{\partial c}{\partial x}+v \frac{\partial c}{\partial y}=D\left(\frac{\partial^{2} c}{\partial y^{2}}\right)
$$

By using the Rosseland approximation, the radiative flux vector $q_{r}$ can be written as:

$$
q_{r}=\frac{4 \sigma^{*}}{3 k^{*}} \frac{\partial T^{4}}{\partial y}
$$


It is assumed that the temperature differences within the flow are sufficiently small so that $T^{4}$ can be expanded in a Taylor series about the free stream temperature $T_{\infty}$ so that after rejecting the higher order terms:

$$
T^{4} \approx 4 T_{\infty}^{3} T-3 T_{\infty}^{4}
$$

The thermal radiation is quite significant and the quality of final product can be controlled by the control of cooling rate via radiation parameter. In polymer industry, the thermal radiation effect may play an important role in the control of heat transfer process if the process is directed in a thermally controlled environment. The desired quality of the final product can be reached by the knowledge of radiative heat transfer.

Where $\mathrm{u}$ and $\mathrm{v}$ are components of the velocity in $x$ and $y$ directions, respectively, $\mathrm{t}$ is the time, $v$ is the kinematic viscosity, $\beta_{T}$ is the volumetric coefficient of thermal expansion, $\beta_{C}$ is the volumetric coefficient of concentration expansion, $\mathrm{g}$ is the acceleration due to gravity, $\rho$ is the density, $\sigma^{*}$ is the StephanBoltzman constant, $k^{*}$ is the Rosseland mean absorption coefficient, $D$ is the coefficient of mass diffusivity, $\bar{\alpha}$ is fluid thermal diffusivity, $c$ is the concentration, $C_{P}$ is the specific heat at constant pressure, $T$ is the temperature and $T_{\infty}$ is the temperature of the fluid far away from the cylinder.

The necessary initial and boundary conditions are:

$$
\begin{array}{lll}
t \leq 0 & u=0, v=0, T=T_{\infty}, c=0 \\
t>0 & u=0, v=0, T=T_{\infty}, c=c_{\infty} \quad \text { at } \quad x=0 \\
t>0 & u=0, v=-v_{0}, T=T_{w}, c=c_{w} & \text { at } \quad y=0 \\
t>0 \quad & u=0, T \rightarrow T_{\infty}, c \rightarrow c_{\infty} & \text { at } \quad y \rightarrow \infty
\end{array}
$$

Now introduce the following non dimensional quantities:

$$
\begin{aligned}
& X=\frac{x}{L}, \quad Y=\frac{y}{L \cdot G r_{T}^{-\frac{1}{4}}}, \quad U=\frac{u L}{v \cdot G r_{T}^{\frac{1}{2}}}, V=\frac{v L}{v \cdot G r_{T}^{\frac{1}{4}}}, \quad R_{d}=\frac{16 \sigma^{*}}{3 k^{*}} \frac{T_{\infty}^{3}}{\mu C_{p}} \\
& C=\frac{c-c_{\infty}}{c_{w}-c_{\infty}}, t^{\prime}=\frac{t \cdot v \cdot G r_{T}^{\frac{1}{2}}}{L^{2}}, \quad \theta=\frac{T-T_{\infty}}{T_{w}-T_{\infty}} G r_{T}^{\frac{1}{4}}, \\
& G r_{T}=\frac{g \beta_{T} L^{3}\left(T_{w}-T_{\infty}\right)}{v^{2}}, G r_{C}=\frac{\beta_{C}\left(C_{w}-C_{\infty}\right)}{\beta_{T}\left(T_{w}-T_{\infty}\right)}, S c=\frac{v}{D}, \operatorname{Pr}=\frac{v}{\alpha}
\end{aligned}
$$

Where a is the cylinder radius, $X, Y$ is dimensionless axis in the direction along and normal to the surface, $U, V$ is the dimensionless velocities, $t^{\prime}$ is the dimensionless time, $\theta$ is the dimensionless temperature, $C$ is the dimensionless concentration, $T_{w}$ is the temperature at the surface, $L$ is the plate length, $G r_{T}$ is the thermal Grashof number, $G r_{C}$ is the mass Grashof number, $R_{d}$ is the radiation parameter, Pr is the prandtl number and $S c$ is the Schmidt number.

Continuity equation:

$$
\frac{\partial U}{\partial X}+\frac{\partial V}{\partial Y}=0(9)
$$


Momentum equation:

$$
\text { (10) } \frac{\partial U}{\partial t^{\prime}}+U \frac{\partial U}{\partial X}+V \frac{\partial U}{\partial Y}=\frac{\partial^{2} U}{\partial Y^{2}}+G r_{T}^{-\frac{1}{4}} \theta+G r_{C} C
$$

Energy equation:

$$
\frac{\partial \theta}{\partial t^{\prime}}+U \frac{\partial \theta}{\partial X}+V \frac{\partial \theta}{\partial Y}=\frac{1}{\operatorname{Pr}} \frac{\partial^{2} \theta}{\partial Y^{2}}-\frac{R_{d}}{\operatorname{Pr}} \frac{\partial^{2} \theta}{\partial Y^{2}}
$$

Concentration equation:

$$
\frac{\partial C}{\partial t^{\prime}}+U \frac{\partial C}{\partial X}+V \frac{\partial C}{\partial Y}=\frac{1}{S c} \frac{\partial^{2} C}{\partial Y^{2}}
$$

The dimensionless boundary conditions become:

$$
\begin{aligned}
& t^{\prime} \leq 0: U=0, V=0 \quad, \theta=0, C=0 \\
& t^{\prime}>0: U=0, V=0 \quad, \theta=0, C=0 \quad \text { at } \quad X=0 \\
& \left.t^{\prime}\right\rangle 0: U=0, V=-V_{0}=S, \theta=1, C=1 \quad \text { at } Y=0 \\
& t^{\prime}>0: U=0, \theta=0, C=0 \quad \text { at } \quad Y \rightarrow \infty
\end{aligned}
$$

In which $S$ is the dimensionless wall-transpiration rate and negative $S$ is blowing rate and positive $S$ is the suction rate.Local skin friction, Nusselt number and Sherwood number. In non-dimensional quantities are:

$$
\begin{aligned}
& C_{f}=G r^{\frac{3}{4}}\left(\frac{\partial U}{\partial Y}\right)_{Y=0} \\
& N u=-G r^{\frac{1}{4}} X \cdot \theta^{\prime}(x, 0, t) \\
& S h=-X G r^{\frac{1}{4}}\left(\frac{\partial C}{\partial Y}\right)_{Y=0}
\end{aligned}
$$

\section{NUMERICAL SOLUTION OF THE PROBLEM}

The governing equations (9-12) are steady, coupled and non-linear with boundary conditions. An implicit finite-difference technique of Crank-Nicolson has been employed to solve the nonlinear coupled equations, as described (Thomas algorithm) in Carnahan et al [25].The finite difference equations corresponding to equations (9-12) are as follows:

$$
\begin{gathered}
\frac{1}{4 \Delta X}\left(U_{i, j}^{n+1}-U_{i-1, j}^{n+1}+U_{i, j}^{n}-U_{i-1, j}^{n}+U_{i, j-1}^{n+1}-U_{i-1, j-1}^{n+1}+U_{i, j-1}^{n}-U_{i-1, j-1}^{n}\right) \\
+\frac{1}{2 \Delta Y}\left(V_{i, j}^{n+1}-V_{i, j-1}^{n+1}+V_{i, j}^{n+1}-V_{i, j-1}^{n+1}\right)=0
\end{gathered}
$$




$$
\begin{aligned}
& \frac{U_{i, j}^{n+1}-U_{i, j}^{n}}{\Delta t^{\prime}}+U_{i, j}^{n}\left[\frac{U_{i, j}^{n+1}-U_{i-1, j}^{n+1}+U_{i, j}^{n}-U_{i-1, j}^{n}}{2 \Delta X}\right]+V_{i, j}^{n}\left[\frac{U_{i, j+1}^{n+1}-U_{i, j-1}^{n+1}+U_{i, j+1}^{n}-U_{i, j-1}^{n}}{4 \Delta Y}\right]= \\
& {\left[\frac{U_{i, j+1}^{n+1}-2 U_{i, j}^{n+1}+U_{i, j-1}^{n+1}+U_{i, j+1}^{n}-2 U_{i, j}^{n}+U_{i, j-1}^{n}}{2 \Delta Y^{2}}\right]} \\
& +G r_{C}\left[\frac{C_{i, j}^{n+1}+C_{i, j}^{n}}{2}\right]+G r_{T}^{-\frac{1}{4}}\left[\frac{\theta_{i, j}^{n+1}+\theta_{i, j}^{n}}{2}\right] \\
& \frac{\theta_{i, j}^{n+1}-\theta_{i, j}^{n}}{\Delta t^{\prime}}+U_{i, j}^{n}\left[\frac{\theta_{i, j}^{n+1}-\theta_{i-1, j}^{n+1}+\theta_{i, j}^{n}-\theta_{i-1, j}^{n}}{2 \Delta X}\right]+V_{i, j}^{n}\left[\frac{\theta_{i, j+1}^{n+1}-\theta_{i, j-1}^{n+1}+\theta_{i, j+1}^{n}-\theta_{i, j-1}^{n}}{4 \Delta Y}\right]= \\
& \left(\frac{1-R_{d}}{\operatorname{Pr}}\right)\left[\frac{\theta_{i, j+1}^{n+1}-2 \theta_{i, j}^{n+1}+\theta_{i, j-1}^{n+1}+\theta_{i, j+1}^{n}-2 \theta_{i, j}^{n}+\theta_{i, j-1}^{n}}{2 \Delta Y^{2}}\right] \\
& \frac{C_{i, j}^{n+1}-C_{i, j}^{n}}{\Delta t^{\prime}}+U_{i, j}^{n}\left[\frac{C_{i, j}^{n+1}-C_{i-1, j}^{n+1}+C_{i, j}^{n}-C_{i-1, j}^{n}}{2 \Delta X}\right]+V_{i, j}^{n}\left[\frac{C_{i, j+1}^{n+1}-C_{i, j-1}^{n+1}+C_{i, j+1}^{n}-C_{i, j-1}^{n}}{4 \Delta Y}\right]= \\
& \left(\frac{1}{S c}\right)\left[\frac{C_{i, j+1}^{n+1}-2 C_{i, j}^{n+1}+C_{i, j-1}^{n+1}+C_{i, j+1}^{n}-2 C_{i, j}^{n}+C_{i, j-1}^{n}}{2 \Delta Y^{2}}\right]
\end{aligned}
$$

The region of integration is considered as a rectangle with sides $X_{\text {max }}(=1)$ and $Y_{\text {max }}(=10)$, where corresponding to $Y_{\text {max }}(=10)$ which lies far from the momentum and energy boundary layers. An appropriate mesh sizes considered for the calculation are $\Delta X=0.01, \Delta Y=0.05$ and $\Delta t^{\prime}=0.005$.

\section{RESULTS AND DISCUSSION}

In this paper, it has been investigated the problem of free convection flow and mass transfer on a vertical plate with radiation and uniform transpiration effects and constant wall temperatures. The velocity, temperature, local skin-friction coefficient and the local Nusselt and Sherwood number profiles for the effect of radiation parameter, thermal Grashof number, mass Grashof number, Prandtl number and Schmidt number are presented graphically in figure 2-22.

The effects of transpiration rate $(S)$, mass Grashof number $\left(G r_{C}\right)$, Schmidt number $(S c)$, radiation parameter $\left(R_{d}\right)$ and thermal Grashof number $\left(G r_{T}\right)$ on the velocity profiles are shown in Figs. 2-6. It is observed that the velocity increases with increase in transpiration rate $(S)$, mass Grashof number $\left(G r_{C}\right)$ and radiation parameter $\left(R_{d}\right)$. Is that the velocity decreases with increase in Schmidt number $(S c)$ and thermal Grashof number $\left(G r_{T}\right)$.

Figs 7-10 display the influence of transpiration rate $(S)$, mass Grashof number $\left(G r_{C}\right)$, radiation parameter $\left(R_{d}\right)$ and Prandtl number. It is clear that increasing the Prandtl number and mass Grashof number tends to decreases the temperature. The hydrodynamics boundary layer become thick as the Prandtl number decreases 
and mass Grashof number. Is that increasing the radiation parameter and transpiration rate tends to increases the temperature

Figs 11-13 illustrates the dimensionless concentration for transpiration rate $(S)$, mass Grashof number $\left(G r_{C}\right)$ and Schmidt number $(S c)$, It is obvious that, the dimensionless concentration decreases with increases in mass Grashof number and Schmidt number. Is that dimensionless concentration increases with increases in transpiration rate.

Figs. 14-17 depicts the local skin-friction coefficient profiles for transpiration rate $(S)$, mass Grashof number $\left(G r_{C}\right)$, radiation parameter $\left(R_{d}\right)$ and thermal Grashof number $\left(G r_{T}\right)$. Then, local skin-friction coefficient profiles decrease with increase in thermal Grashof number and increase with increase in transpiration rate, mass Grashof number and radiation parameter.

The influence of transpiration rate $(S)$, mass Grashof number $\left(G r_{C}\right)$ and radiation parameter $\left(R_{d}\right)$ on the local Nusselt number profiles are shown in Figs. 18-20. It is observed that the local Nusselt number increases with increase in transpiration rate and mass Grashof number. As well as the local Nusselt number decreases with increase in radiation parameter.

The influence of transpiration rate $(S)$ and Schmidt number $(S c)$ on the local Sherwood number profiles are shown in Figs. 21-22. It is observed that the local Sherwood number decreases with increase in transpiration rate. As well as the local Sherwood number increases with increase in Schmidt number.

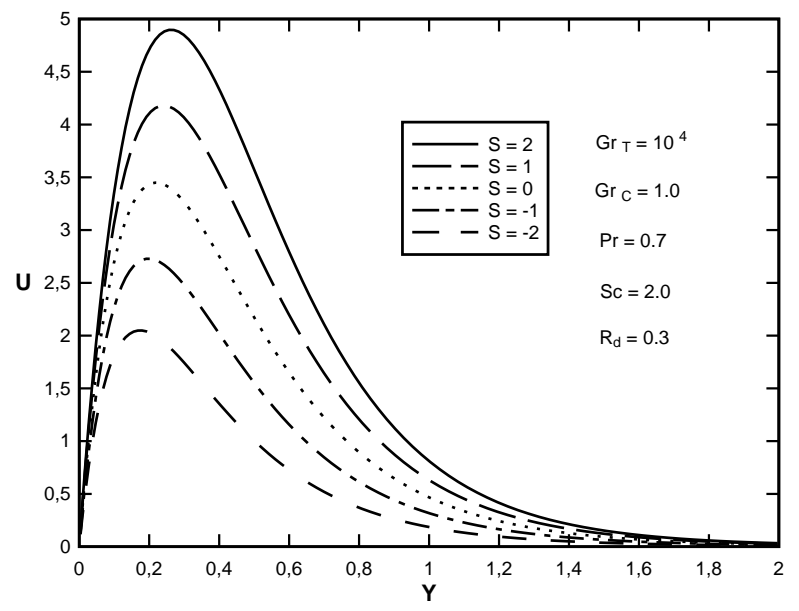

Figure 2: Effect of transpiration rate $(S)$ on dimensionless velocity Profiles

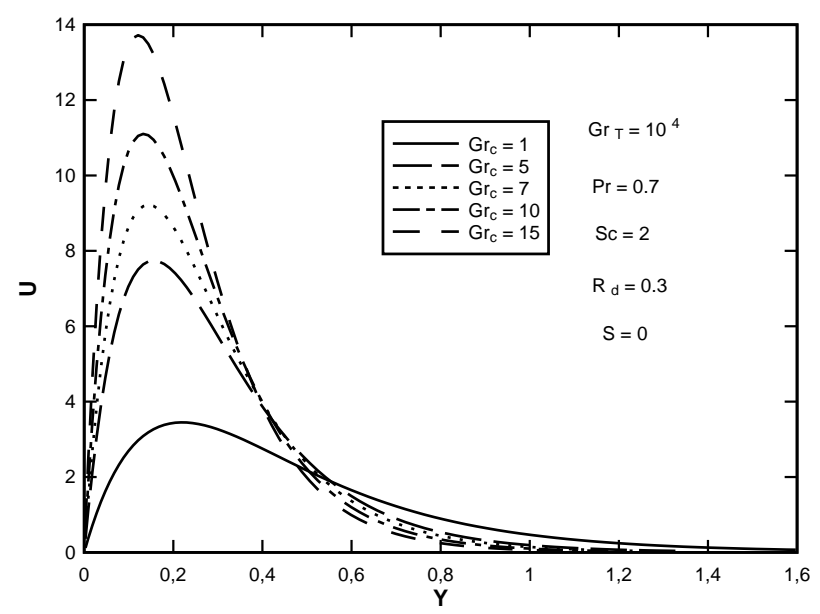

Figure 3: Effect of mass Grashof number $\left(G r_{C}\right)$ on dimensionless velocity Profiles 


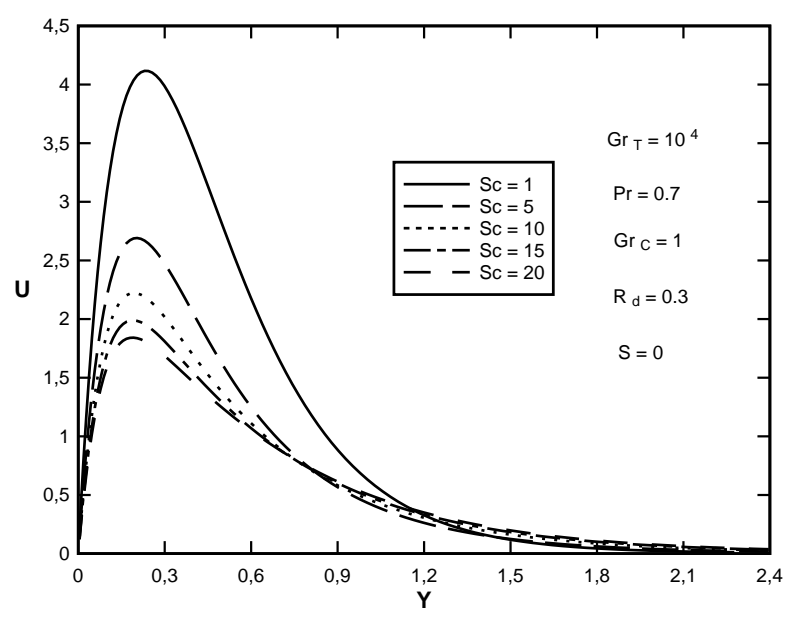

Figure 4: Effect of Schmidt number ( $S c$ ) on dimensionless velocity Profiles

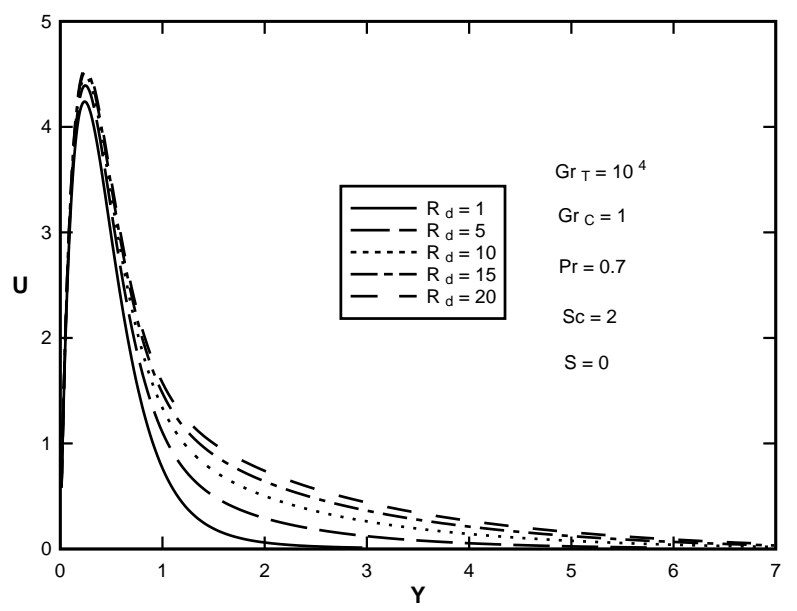

Figure 5: Effect of radiation parameter $\left(R_{d}\right)$ on dimensionless velocity Profiles

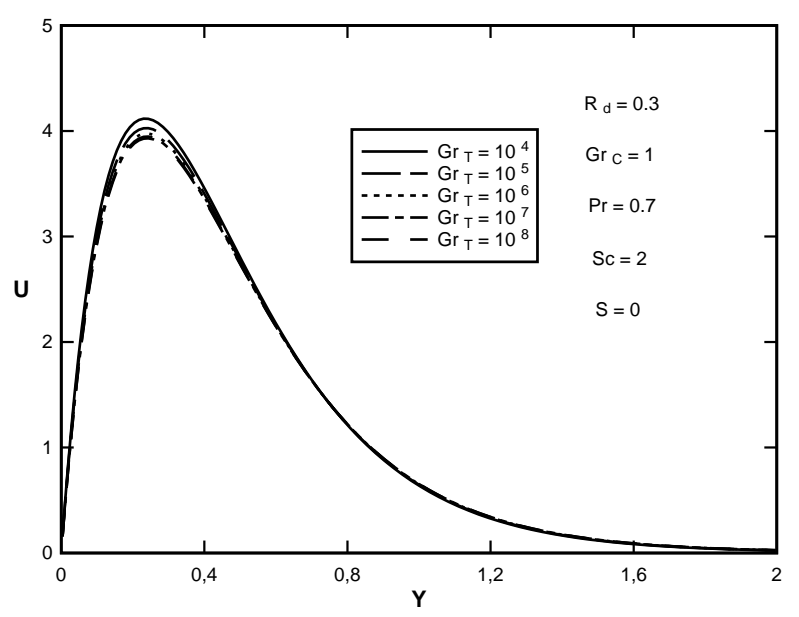

Figure 6: Effect of thermal Grashof number $\left(G r_{T}\right)$ on dimensionless velocity Profiles 


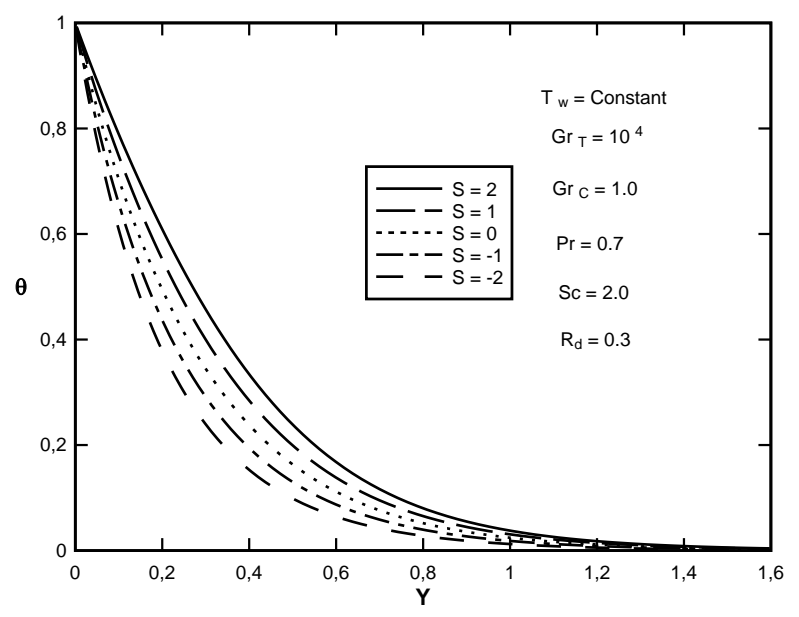

Figure 7: Effect of transpiration rate $(S)$ on dimensionless temperature Profiles

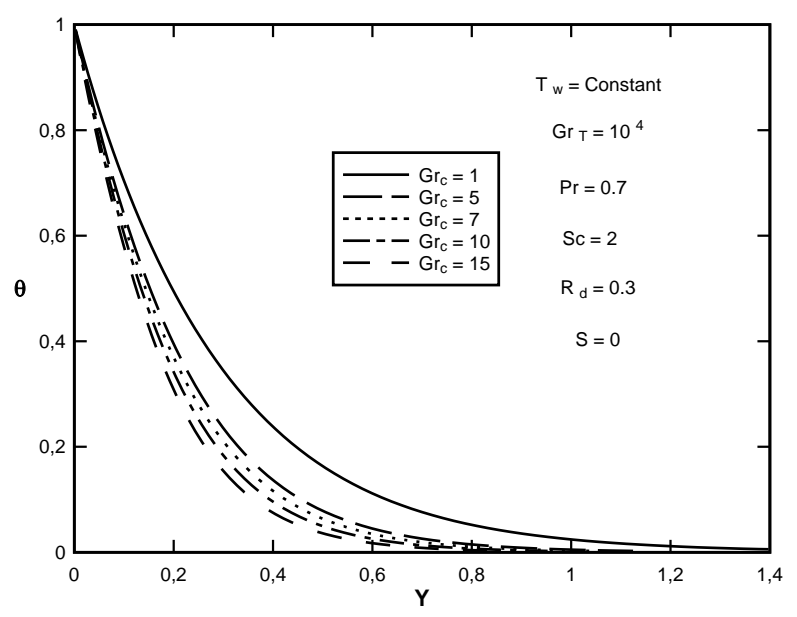

Figure 8: Effect of mass Grashof number $\left(G r_{C}\right)$ on dimensionless temperature Profiles

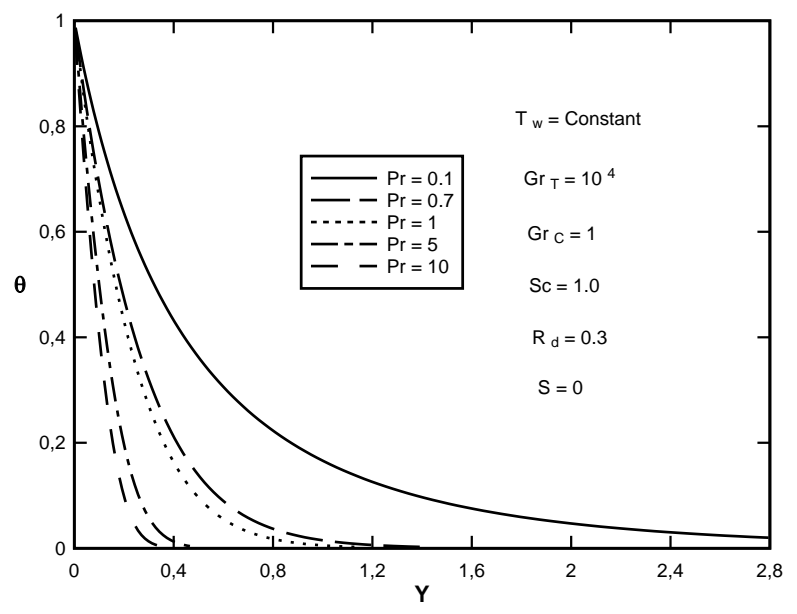

Figure 9: Effect of Prandtl number (Pr) on dimensionless temperature Profiles 


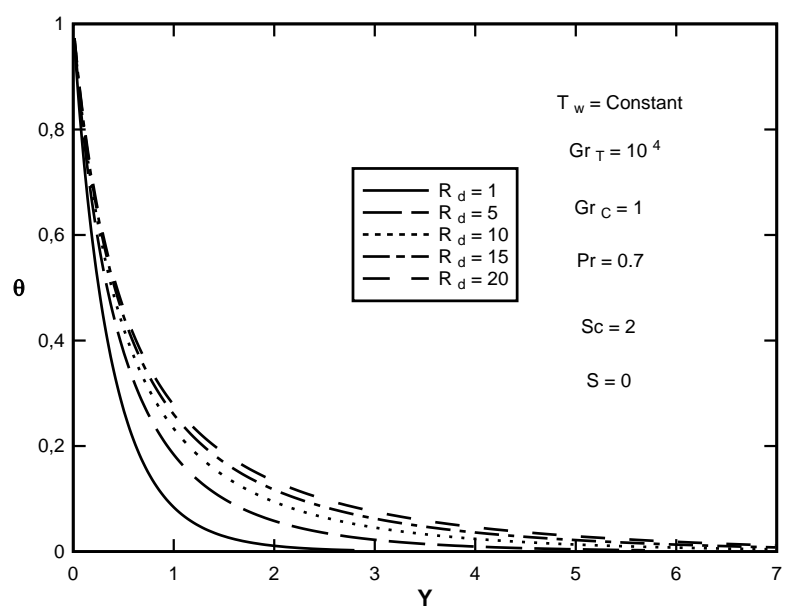

Figure 10: Effect of radiation parameter $\left(R_{d}\right)$ on dimensionless temperature Profiles

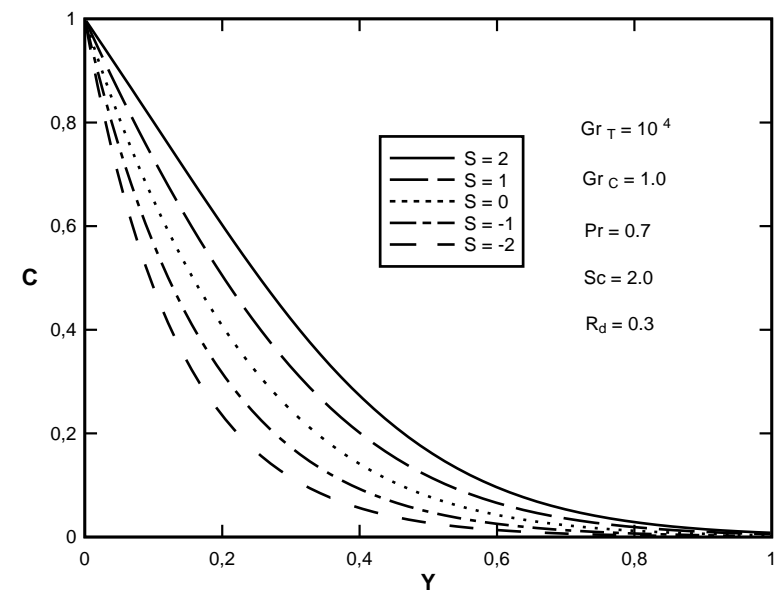

Figure 11: Effect of transpiration rate $(S)$ on dimensionless concentration Profiles

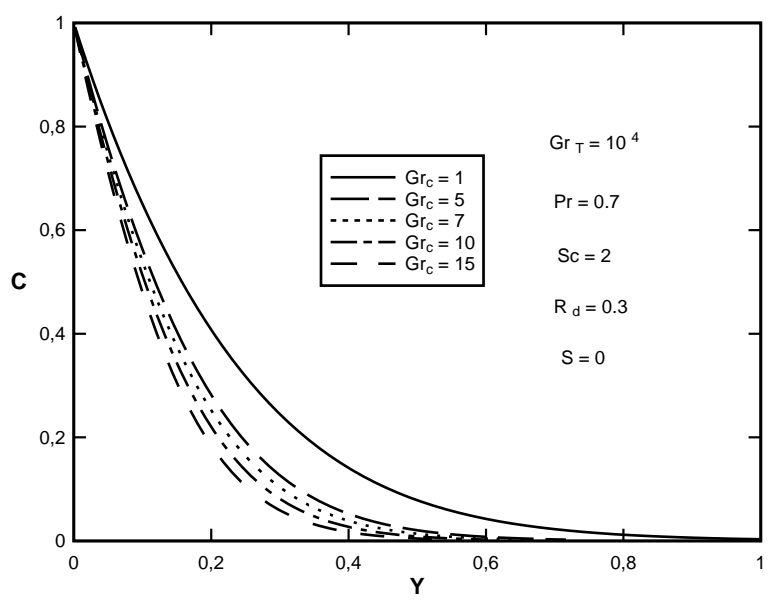

Figure 12: Effect of mass Grashof number $\left(G r_{C}\right)$ on dimensionless concentration Profiles 


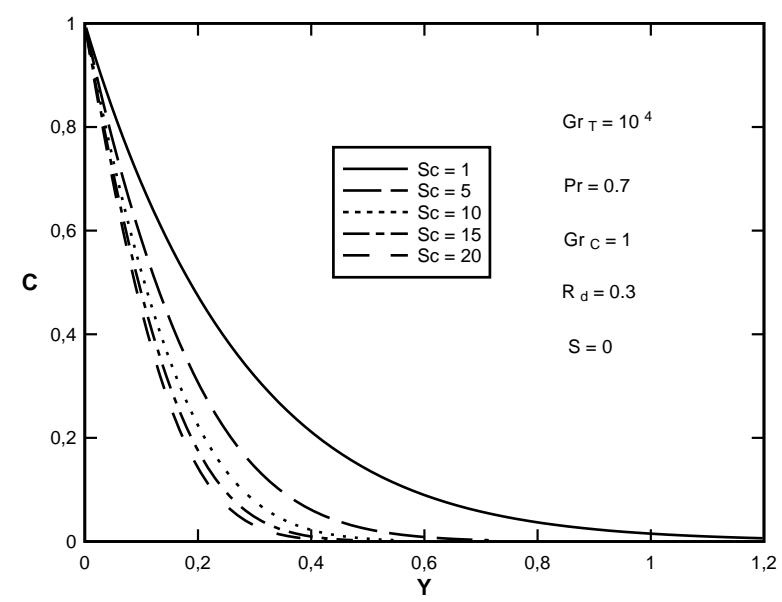

Figure 13: Effect of Schmidt number ( $S c$ ) on dimensionless concentration Profiles

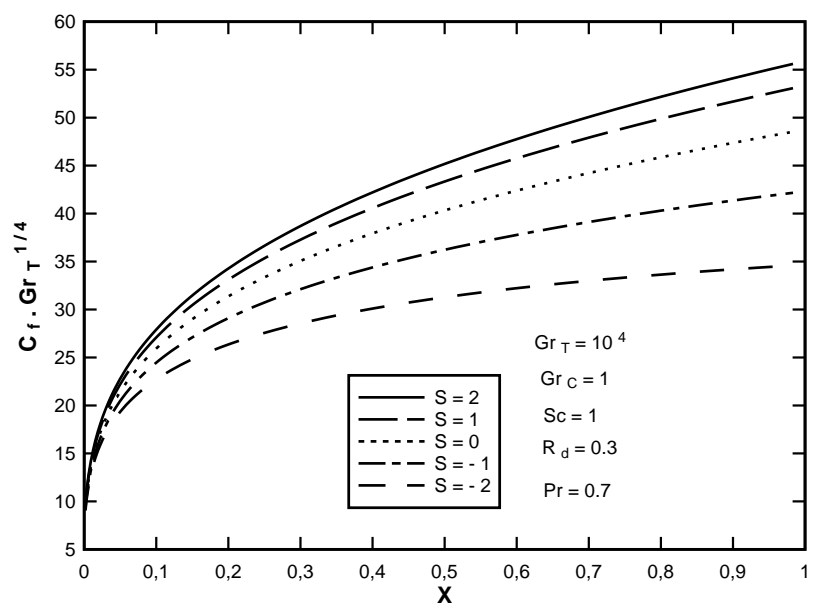

Figure 14: Effect of transpiration rate $(S)$ on local skin-friction coefficient Profiles

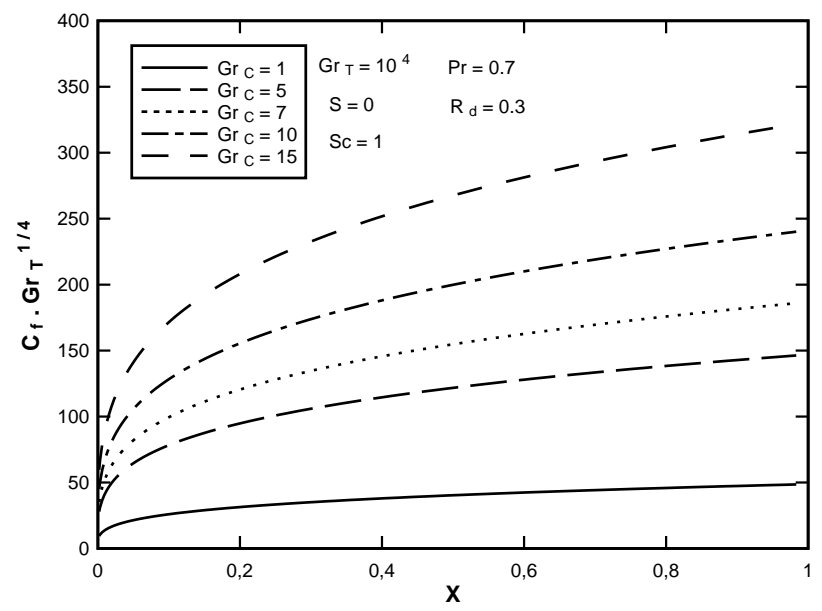

Figure 15: Effect of mass Grashof number $\left(G r_{C}\right)$ on local skin-friction coefficient Profiles 


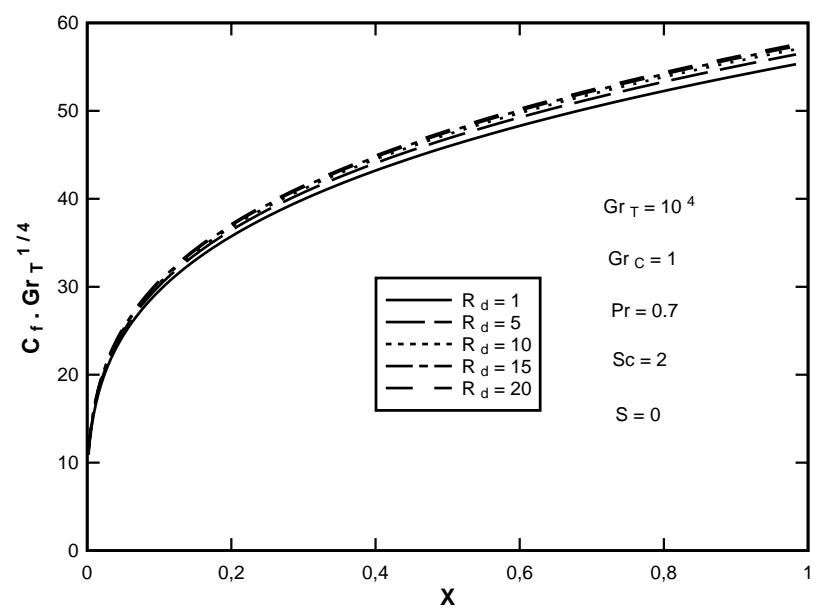

Figure 16: Effect of radiation parameter $\left(R_{d}\right)$ on local skin-friction coefficient Profiles

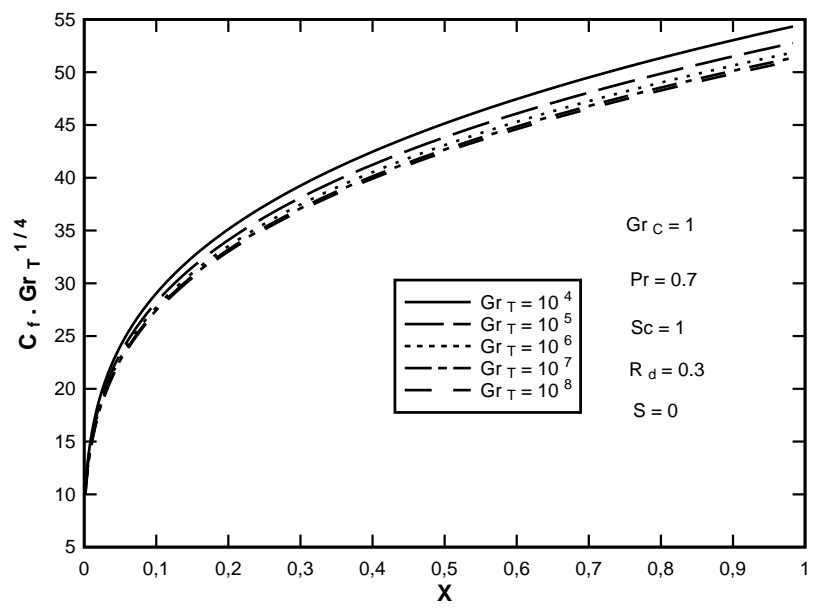

Figure 17: Effect of thermal Grashof number $\left(G r_{T}\right)$ on local skin-friction coefficient Profiles

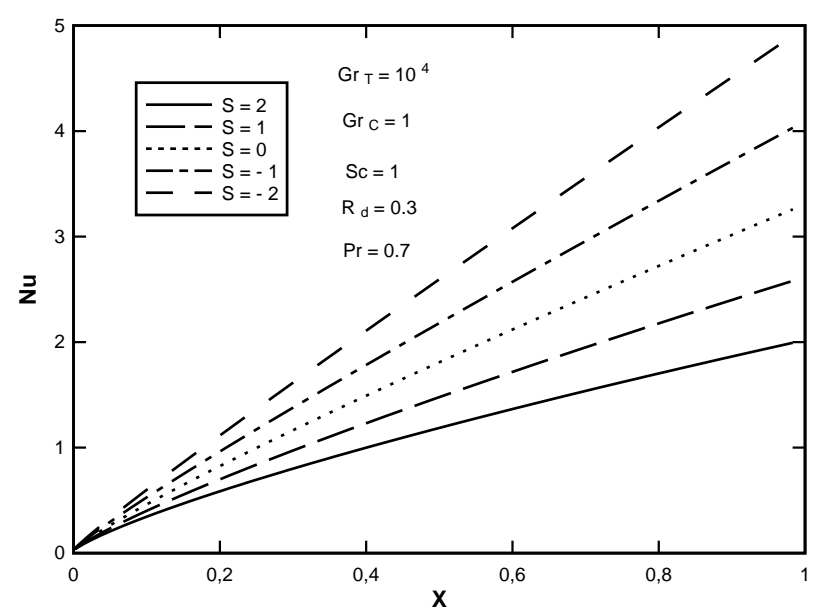

Figure 18: Effect of transpiration rate $(S)$ on local Nusselt number Profiles 


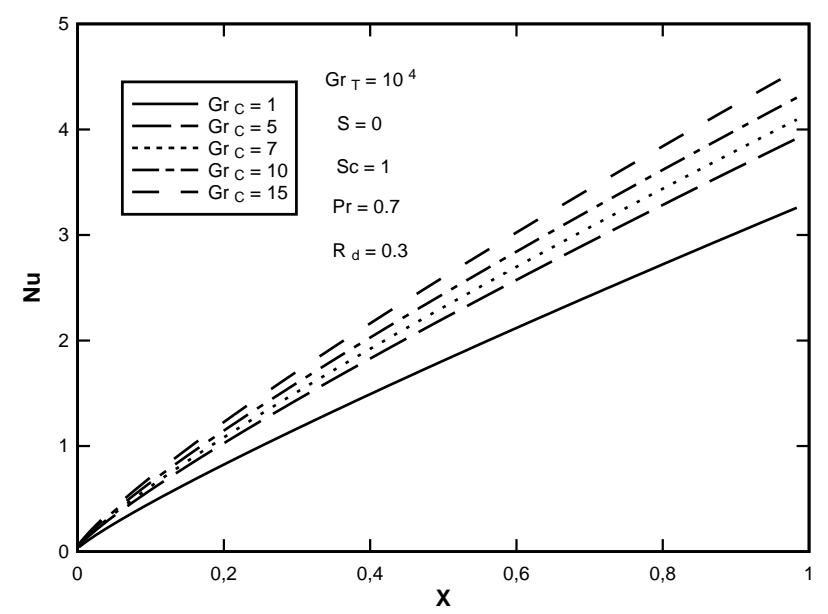

Figure 19: Effect of mass Grashof number $\left(G r_{C}\right)$ on local Nusselt number Profiles

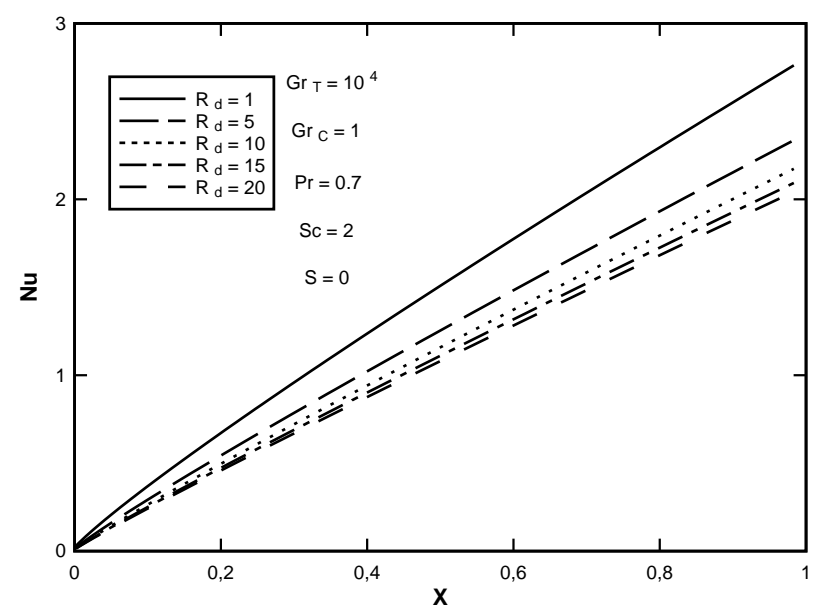

Figure 20: Effect of radiation parameter $\left(R_{d}\right)$ on local Nusselt number Profiles

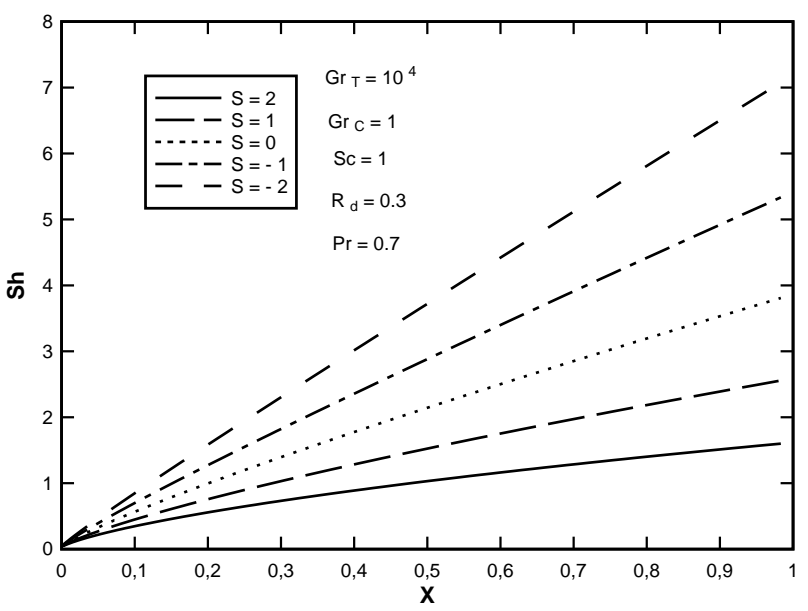

Figure 21: Effect of transpiration rate $(S)$ on local Sherwood number Profiles 


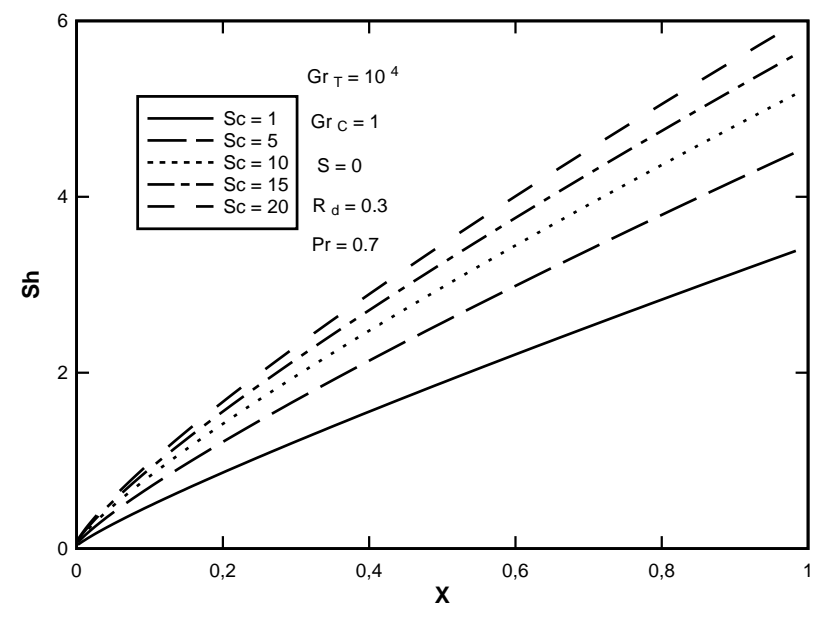

Figure 22: Effect of Schmidt number (Sc ) on local Sherwood number Profiles

\section{References}

[1] Soundalgekar VM and Wavre PD. Unsteady free convection flow past an infinite vertical plate with constant suction and mass transfer. International Journal of Heat and Mass Transfer, 20, (1977) pp.1363-1373.

[2] A.A. Raptis, N.kafousias, Heat transfer in flow through a porous medium bounded by infinite vertical plate under the action of magnetic field, Int. J. Energy Res. 10, (1986), pp. 97-100.

[3] M.Y. Gokhale, Magnetohydrodynamic transient-free convection past a semi-infinite vertical plate with constant heat flux, Can. J. Phys. 69, (1991), pp.1451-1453.

[4] H. S. Takhar, P. Ganesan, K. Ekambavahar, and V. M. Soundalgekar, Transient free convection past a semi-infinite vertical plate with variable surface temperature, Internat. J. Numer. Methods Heat Fluid Flow 7 (1997), 280-296.

[5] B. Gebhart, L. Pera, The nature of vertical natural convection flows resulting from the combined buoyancy effects of thermal and mass diffusion, Int. J. Heat Mass Transfer 14 (1971) 323-329.

[6] G.D. Callahan, W.J. Marner, Transient free convection with mass transfer on an isothermal vertical flat plate, Int. J. Heat Mass Transfer 19 (1976) 165-174 .

[7] V.M. Soundalgekar, P. Ganesan, Finite difference analysis of transient free convection with mass transfer on an isothermal vertical flat plate, Int. J. Eng. Sci. 19 (1981) 757-770 .

[8] K. Ekambavannan, P. Ganesan, Finite difference analysis of unsteady natural convection along an inclined plate with variable surface temperature and mass diffusion, W€arme Stoff€ubertrag . 31 (1995) $17-24$.

[9] V.M. Soundalgekar, S.K. Gupta, N.S. Birajdar, Effects of mass transfer and free convection effects on MHD Stokes problem for a vertical plate, Nucl. Eng. Des. 53 (1979) 309-346.

[10] N.C. Sacheti, P. Chandran, A.K. Singh, An exact solution for unsteady magnetohydrodynamics free convection flow with constant heat flux, Int. Commun. Heat Mass Transfer 21 (1994) 131-142.

[11] Sattar MA, Rahman MM, and Alam MM. Free convection flow and heat transfer through a porous vertical plate immersed in a porous medium with variable suction. Journal of Energy, Heat and Mass Transfer, 21, pp.17-21 (2000)

[12] Emad M. Abo-Eldahab, Ahmed M. Salem, MHD free-convection flow of a non-Newtonian power-law fluid at a stretching surface with a uniform free-stream, Journal of Applied Mathematics and Computation, (2005) 169

[13] M.A. Abd El-Naby, Elsayed M.E. Elbarbar, Nader Y. AbdElazem, Finite difference solution of radiation effects on MHD unsteady free-convection flow over vertical porous plate, Journal of Applied Mathematics and Computation, (2004) 151.

[14] Youn J. Kim, Unsteady MHD convection flow of polar fluids past a vertical moving porous plate in a porous medium, International Journal of Heat and Mass Transfer, (2001) 44. 
[15] P.R. Sharma and G. Singh, Unsteady MHD free convection and heat transfer along a vertical porous plate with variable suction and internal heat generation, Int. J. of Appl. Math and Mech, (2008) 4.

[16] P. Ganesan, G. Palani, Numerical solution of unsteady MHD flow past a semi-infinite isothermal vertical plate, in: Proceedings of the sixth ISHMT/ASME Heat and Mass Transfer Conference and Seventeenth National Heat and Mass Transfer Conference, Kalpakkam, India, January 5-7, 2004, pp. 184-187.

[17] P. Ganesan, G. Palani, Convective flow over an inclined plate with variable heat and mass flux, in: Proceedings of the Fourth ISHMT/ASME Heat and Mass transfer Conference and Fifteenth National Heat and Mass Transfer Conference, Pune, India, January 12-14, 2000, pp. 323-329.

[18] B. Shanker, N. Kishan, The effects of mass transfer on the MHD flow past an impulsively started infinite vertical plate with variable temperature or constant heat flux, J. Energy, Heat Mass Transfer 19 (1997) 273-278 .

[19] H.S. Takhar, A.J. Chamkha, G. Nath, Unsteady mixed convection flow from a rotating vertical cone with a magnetic field, Heat and Mass Transfer 39 (2003) 297-304.

[20] E.M.A. Elbashbeshy, Heat and Mass transfer along a vertical plate with variable surface tension and concentration in the presence of the magnetic field, Int. J. Eng. Sci. 34 (5) (1997) 515-522.

[21] K.A. Helmy, MHD unsteady free convection flow past a vertical porous plate, ZAMM 78 (1998) 255270.

[22] S. Kakac, Y. Yener, Convective Heat Transfer, CRC Press Inc, Boca Raton, FL, 1995.

[23] I.A. Hassanien, A.A. Abdullah, R.S. Gorla, Math. Comput. Model. 28 (1997) 105.

[24] R.B. Bird, W.E. Stewart, E.N. Lightfood, Transport Phenomena, John Wiley, New York, 1960.

[25] B. Carnahan, H.A. Luther, J.O. Wilkes, Applied Numerical Methods, John Wiley and Sons, New York, 1969. 